\title{
Wart $\mathbf{f}$ ifth.
}

\section{MEDICAL NEWS.}

\section{MEDICO-CHIRURGICAL SOCIETY OF EDINBURGH.}

\author{
Session XXIX.-Meeting VII.-February 20, 1850.-Dr Bennett, Vice- \\ President, in the Chair.
}

\section{CAVITY IN THE LUNG.}

Dr Spittal produced the lung of a woman who had been recently found dead, and of whose early history nothing was known. The apex of the left lung was adherent to the wall of the chest, and contained a cavity of the size of a walnut, lined with a bluish-white semi-transparent fibrous membrane. The cavity did not communicate with the bronchi ; the pulmonary tissue surrounding it was infiltrated with black pigment, and contained a few small hard and greycoloured masses resembling chronic tubercle. A few similar masses were found in the other lung towards its apex. When microscopically examined, they were seen to consist of an irregular corpuscular element. Dr S. was inclined to regard the preparation as illustrative of the spontaneous cure of tubercular disease of the lung.

Dr Bennett, on examining the specimen, said that his impression was, that this was not an example of a tubercular cavity. There was no hardening round it, no distinct evidence of tubercle in the other lung, while the appearance of the cavity at once suggested the probability of its being a dilated bronchus. He exhibited a coloured lithographic drawing, which gave a good view of the appearances presented by the cicatrices of tubercular deposits in the lungs.

Dr W.T. Gairdner said, that diminution in size, and even cicatrization of cavities, was not unfrequently seen in lungs in which the tubercular deposition was in active progress in other parts, and when there could be no reasonable doubt, therefore, that the cavities were tubercular in their character. The same might be said of calcareous concretions, which were frequently found in lungs, where, in other parts, tubercles were advancing, and where their formation from tubercle was self-evident. The spontaneous cure of tubercle in the lung, in so far as relates to the drying up of tubercular matter, and the healing of tubercular ulcers, was abundantly proved by the facts of morbid anatomy, when viewed on a large scale. But in regard to individual specimens, such as the one before the Society, there was almost always a good deal of difficulty, arising from the fact, that concretions are formed in the lung from every kind of effete exudation; and that cavities, too, of a very different mode of origin from tubercular ulceration, underwent precisely the same transformation as these. The extremely smooth and glistening appearance of the membrane, the character of the surrounding tissue, and the very scanty evidence of the existence of tubercular matter, at least to such an extent as to cause so large an ulcer, combined to render it very probable that the cavity in Dr Spittal's case was not tubercular. Dr G. indicated several modes in which cavities were formed in the lungs, and mentioned his intention of shortly exhibiting to the Society some drawings and preparations illustrating this subject.

Dr Spittal was inclined to retain his original opinion, which was strengthened by the facts, that the cavity did not communicate with the bronchi at all, and that it was surrounded by small grey and hard masses, which he believed to be tubercle in the chronic state.

Some conversation followed upon the subject of the sanability of phthisis, in 
which Dr Maclagan, Dr Bennett, Dr Myrtle, and Dr Taylor took part. Dr Simpson related one remarkable case which had occurred in his own practice, in which a young man, of a delicate family, after suffering from most of the general symptoms of consumption, and exhibiting the physical signs of the disease, emigrated to Australia, lived there for sixteen years, and finally died of a totally different complaint.

Dr Seller remarked, that the old practitioners had a term, "catarrhal phthisis," under which they included all cases of hectic fever, with purulent expectoration and emaciation, which recovered. They were pleased to doubt the possibility of recovery in cases of true phthisis ; but modern researches had rendered it all but certain, that many cases of tubercular phthisis were erroneously referred to the class of catarrhal or sanable consumption.

Dr John Gairdner made some observations upon the comparative infrequency of phthisis in certain rural districts, and particularly to the alleged immunity from the disease enjoyed by the inhabitants of Australia. It had been stated, that the few cases observed in the Australian colonies were imported from Europe.

\section{TUMOUR OF SUPRA-RENAL CAPSULE.}

Dr W. T. Gairdner read a communication from Mr Craig, surgeon, Ratho, giving an account of a case of malignant disease of the supra-renal capsule, which had lately occurred in his practice. The patient, when 84 years of age, sustained a severe injury by a cart falling upon him and bruising the loins. After a few days' confinement he recovered, and for twenty-six years continued healthy and robust. In February 1846, after some violent exertion, he passed some bloody urine with considerable pain, but in a few days became to all appearance as healthy as ever. In April 1849, he began to suffer from neuralgic pain of the right hip and leg, most severe when he was in a sitting posture ; the general health at this time was good, and no urinary symptoms were observed. The abdomen was carefully examined, and no tumour detected. In July the course of the left sciatic nerve became the chief seat of pain; and pressure from behind over the seat of the left kidney aggravated his sufferings. Flatulent distension of the bowels, capricious appetite, and restless nights, soon followed ; the patient, after a variety of treatment, lost flesh considerably ; and, finally, towards the end of July, a hard distinct tumour, as large as a melon, and perfectly moveable, could be felt in the left hypochondrium. Dr Begbie now saw the patient along with $\mathrm{Mr}$ Craig, and after careful examination, was at a loss to decide upon the precise nature of the tumour, but suspected the kidney to be the viscus implicated. The urine contained large crystals of oxalate of lime, likewise uric acid crystals, and amorphous matter. Rapid emaciation was now observed; the lower extremities became gradually paralysed ; the sufferings of the patient were most acute, and in January 1850 the case terminated fatally.

Sectio Cadaveris.-A large tumour behind the descending colon occupied the whole of the left hypochondrium, extending from the diaphragm to the ilium, and displacing the spleen towards the centre of the cavity. It was firmly adherent to the lower dorsal and lumbar vertebræ, and to the lower ribs for two or three inches from their vertebral articulations. Large pieces of bone were laid bare, and many exfoliations were separated from the vertebræ, and were so firmly united to the growth by ligamentous bands, as to be torn away with difficulty.

Dr W. T. Gairdner gave the following account of the tumour, which was exhibited to the Society. "It was attached to the upper part of the kidney, three-fourths of the substance of which was sound. The upper margin of the kidney was altered in form, flattened, and separated by a thick band of cellular tissue from the main mass of the tumour, which occupied the situation of the supra-renal capsule. Two or three rounded masses of morbid matter, similar to the tumour, lay between the infundibula, among the cellular and fatty tissue 
exterior to the pelvis. Pelvis, ureter, veins, and arteries were all sound, and I presume these morbid masses were parts of the lymphatic system. The tumour consisted, for the most part, of matter of a tolerably firm consistence, and of a yellowish-grey colour, tinged very deeply at the upper part with blood, which was apparently extravasated. In its general arrangement, the yellowish matter bore considerable resemblance to that which is found in the normal suprarenal capsule of the adult, except that there was no distinct cavity, and the central yellow matter was enormously increased in bulk. On examining a portion of this matter with the microscope, I found cells, fibres, and a large quantity of granular matter ; but none of these elements were in any way characteristic ; and, indeed, the cell-structure seemed to constitute a small part of the tumour.

"It is difficult to form a positive opinion as to the malignant or non-malignant character of this tumour. It may be a mere hypertrophy with fatty degeneration of the supra-renal capsule, or it may be a cancerous infiltration of it. In the former case, it may be an exaggeration of the foetal condition, though in such a case it would be difficult to explain why one gland only was thus affected. I may also state, that from an examination with low powers, made after the parts had been placed in spirits, I have not been able to find any of the tubular arrangement so readily seen in the cortical substance of the suprarenal capsule. From this and other circumstances, I am disposed to consider the tumour cancerous, - a view which is also supported by the presence of nodules in the lympathic system of the kidney."

HEMORRHAGIC MEMBRANE WITHIN THE ARACHNOID.

Dr W. T. Gairdner exhibited preparations illustrating the morbid appearances found in a case of a melancholic patient in the Edinburgh Asylum, who had been insane for several months before death. On removing the skull-cap, the outer surface of the dura matter was quite normal; but its inner surface was coated with a thin membrane, composed of fibrine, mostly of a yellowishwhite or very pale rust colour, and involving here and there small irregularshaped portions of purple coloured fibrine, in all respects similar to clots of blood. This membrane was thickest in the neighbourhood of the falx cerebri, where it was reflected from the dura mater over the cerebral arachnoid, and had a thickness of about two lines. It was readily traced upon both sides of the falx, passing to left and right, one portion covering the arachnoid of the dura mater, the other the cerebral arachnoid over the whole of the superior, anterior, and posterior convolutions of both hemispheres. At the lower lateral parts of the brain it became very much attenuated, being lost altogether at the base of the brain. Although closely adherent to the arachnoid membrane, it could be stripped off readily enough, leaving the surface nearly as smooth as in the natural condition, and with no trace of unusual vascularity. The free surface of the membrane was also apparently smooth and glistening, like that of serous tissue. The microscopic structure of the membrane was that of decolorised fibrine, with some indefinite nuclei, and some granular matter. There were no distinct appearances of vessels, or of fibrous tissue, other than the filaments which are found in all fibrine.

Dr G. adverted to the observations of various authors, and particularly to the elaborate papers of Mr Prescott Hewett, in the "Medico-Chirurgical Transactions," vol. xxviii. ; and the preparations by the same gentleman in St George's Hospital Museum, as proving the origin of such membranes from extravasation of blood. He said that inflammatory effusion within the cavity of the arachnoid was a very rare occurrence, except as the direct result of injuries or operations involving the cranial bones and dura mater. In all ordinary cases of meningitis, the lymph was effused among the vessels of the pia mater, and beneath the cerebral arachnoid, being therefore external to the arachnoid cavity.

Dr Bennett quite agreed with the view of the nature of the case which Dr W. T. Gairdner had propounded. He had himself seen appearances somewhat similar in a dissection conducted at Berlin by Romberg. 


\section{Meeting VIII.-Wednesday, 6th March 1850.-Dr Begbie, Vice-President, in the Chair.}

Professor Miller read an account of a case of Inguinal Aneurism, which will be found among the Original Communications, page 318.

HEMORRHAGE FROM A UTERINE POLYPUS.

Dr Patrick Brown, of Whitchurch, Salop, detailed a case, in which the passage of a uterine polypus had caused extreme hemorrhage. The patient, a poor woman, residing about three miles from Whitchurch, had been for some time in bad health, had observed some bloody discharge from the vagina for a few days, and finally, on the day when Dr B. was sent for, the hemorrhage had become so profuse, that on his arrival he found her anemic and almost pulseless, her extremities cold, and her face bedewed with cold clammy sweat. She was still sensible, and could articulate in a feeble whisper. The bed was saturated with blood. The woman had suffered from pains resembling those of labour, and believed that she was about to miscarry. On making an examination per vaginam, the os and cervix uteri were found dilated with a round firm substance, of the size of a pullet's egg. Its uterine attachment could not be reached with the finger; but by twisting the whole mass round and round, Dr B. succeeded in bringing it away. It proved to be a pear-shaped fibrous polypus, which had been suspended by a narrow pedicle. The patient's abdomen was now tightly bound with a shawl, the vagina was plugged with some wet rags, warm bricks were applied to the extremities, and stimulants freely administered. The patient soon rallied, and ultimately recovered, although for years she continued to present a most ghastly appearance. The author concluded his communication, by expressing his sense of the practical value of Dr Simpson's recent essay on uterine polypi ; and by lamenting that mistaken feelings of delicacy on the part of patients and their friends, often prevented the general practitioner in England from instituting a vaginal examination,- the only mode by which the true character of any disease of the internal female organs can be ascertained.

Dr Simpson believed that the false delicacy to which Dr Brown had alluded was in some degree attributable to the questions which medical attendants often put, - e. g., asking the consent of their patient before proceeding to examine the vagina. Here the examination was never prefaced with such questions.

Some conversation followed between Dr J. Gairdner, Dr Simpson, Dr Moir, Dr Begbie, and Dr Skae, regarding the amount of blood which could be abstracted without inducing death. The smallest loss of blood which was known to have proved fatal was seventeen ounces, - the amount lost by the Princess Charlotte. The amount of hemorrhage which could be borne by healthy women, not exhausted by labour or previous illness, could not be estimated.

Dr W. T. Gairdner having inquired whether Dr Simpson could throw any light upon the source of hemorrhage in cases of uterine polypi ? Dr S. replied, that in certain cases of profuse hemorrhage lasting for months, which had fallen under his own observation, he believed that the blood proceeded, not from any laceration, but from the mucous surface of the tumour. If, as some authors asserted, the bleeding took place from the mucous surface of the uterus, why should hemorrhage cease when the polypus was tied?

\section{ON A PECULIAR DISEASE OF THE NASAL FOSSA.}

Dr John Gairdner read the following communication :-

The diseases of medical men are of special interest to the profession, on this account, that they are closely observed by those who are capable observers of pathological phenomena ; and, as the author of a celebrated treatise on the culinary art is said to have proved his precepts by fairly eating through all the dishes recommended in his volume, so a physician, whose fortune it should 
be to encounter the scarcely more dangerous, though far less agreeable, ordeal of tasting all the various curable ills that flesh is heir to, would possess high advantages for writing an instructive work on the history, diagnosis, and treatment of diseases. I venture to think that the following case, which is that of a medical gentleman, may possess some interest, not merely on this principle, but as being an example of a somewhat unusual form of disease; which, resulting in a recovery, may serve to guide us to a favourable prognosis in future cases of the same description.

The subject of my narrative was above fifty years of age, when he became affected with a common coryza of no unusual severity. While labouring under it, he was called to a piece of professional duty at a considerable distance. It was early in May, and he had to travel twelve miles of his journey in an open vehicle, and under a chilly atmosphere,- the last four miles being after sunset. His coryza was thus very sensibly increased, and it became still more troublesome after his return. A week after the date of his journey he was obliged to take to bed for four days, in consequence of feverishness, headach, and excessive coryza ; which last symptom was then, for the first time, attended with a most distressing fetor. The fetor proceeded exclusively from the right nostril, from which also the discharge chiefly came. The matter was thick and opaque. There was considerable pain in the right superior-maxillary region, and also behind the mastoid process, at a point about one inch below the insertion of the right trachelo-mastoid muscle. The discharge, which was at first excessive, gradually diminished, along with the other symptoms, and he was enabled to resume his professional duties in less than a week from the time he took to bed.

Such was the commencement of a disorder, which hung about him, in a subdued form, for several years. After the subsidence of the acute symptoms, his ordinary condition was as follows :- He had,-1. a constant sense of partial obstruction of the right nostril, requiring some degree of force to impel air through it ; 2 . more than the usual amount of mucous discharge from that nostril ; 3 . inability to incline his head forward without causing a necessity for the use of his handkerchief; 4 . fetor, not constant, nor even frequent, as it occurred only once or twice a-day, and for a minute or thereabouts at a time ; rarely perceptible by others; always accompanied, when it did occur, by a sensation of the escape of some fluid into the affected nostril ; and usually followed by the discharge of a pellet of matter, which was thicker and yellower than the ordinary mucus of the nostril ; 5 . pain in the region of the right superior maxillary bone ; it was a dull pain, not constant, but seldom absent for above a day, or two days at most. 6. To these things I must add, that the discharges from the two nostrils, microscopically examined, presented very different characters - that of the right nostril containing pus globules, while that of the left exhibited no characters at all different from those of the healthy secretion of the Schneiderian membrane. All these symptoms, and especially the fetor, were immediately and greatly increased by every inflammatory cold which affected the nasal fossa.

After the lapse of seven years and a half from the first invasion of this disagreeable disorder, he was lately seized with a catarrhal affection, accompanied by coryza, fetid discharge from the nostril, and some headach. The attack was in no respect different from many attacks which he had had at various periods for some years before it. But, immediately after its cessation, he remarked with satisfaction that the fetor was gone, and the habitual discharge from the right nostril greatly diminished. The sense of obstruction in the nostril, the stillicidium upon inclining the head forward, and the pain in the maxillary region, had all undergone a great change for the better. The change has been progressive, - and he is now so free from all these symptoms, that his cure may be regarded as nearly complete.

On a retrospect of this case, it appears probable that the exposure in which NEW SERIES.-NO. IV. APRIL 1850. 
it originated had caused the death of a minute portion of bone within the nostril, possibly of a part of the spongy bone, and that the exfoliation of this portion was the cause of the cure. That its escape was not observed by the patient is not against this supposition; as a very inconsiderable fragment would suffice to account for every thing.

It may be right that I should make this history complete, by stating that the patient is of a healthy constitution, that he has not been subject to glandular swellings, or any form of strumous disorder, that he never took mercury except in the form of a purgative of calomel, and that not half a dozen times in his life, so far as he can remember; and that he never in his life had any description of venereal disorder.

Two things must be mentioned with regard to his family. One is, that his mother certainly suffered from some analogous affection some years before her death ; she did not indeed complain of it, and therefore he cannot supply any minute information about it ; but her handkerchief gave sufficient evidence of more than usual discharge from the nostrils, and of its being thick, and, as he thinks, somewhat fetid.

The other fact alluded to is of more interest. His brother, who is also of the medical profession, experienced a similar attack in his own person. In him the complaint did not supervene suddenly, but was the result of repeated and neglected colds. For forty years of his life he scarcely ever required the use of a pocket-handkerchief. For two years he used two every day; and, when dry, they were always glued together in the manner that is caused by a discharge from an excited mucous surface. The discharge was manifestly fetid at times, though not constantly. This was not felt by himself, for the sense of smelling was then, and still continues to be, much blunted. After two years, during which time the discharge had flowed pretty copiously, and at times so freely as to be a very great inconvenience, a gradual abatement was observed; and, about this period, he was aware of some traces of osseous matter. The right nostril was much more affected than the left, but his pain was confined to the region of the frontal sinuses, and was dull, not acute. $\mathrm{He}$ has still a constant moisture of the right nostril, which becomes copious, not with colds only, but with any disturbance of health, and has occasional fetor. He thinks the sense of smelling is returning. He still uses a handkerchief every day; but he remarks, that when it is dry, it is not now, as it formerly used to be, hard and stiff as a board. It is, therefore, evident that a great change has taken place, indicating a diminution of fibrinous exudation, and an approximation to a cure of his disease.

Under the title ozœna, in a variety of systematic works, will be found descriptions of a form of disease similar to the above, which are usually accompanied by an unfavourable opinion with regard to the chance of its removal. The prognostic, I have no doubt, is well founded in many instances. But I am inclined to think that where, as in the cases just related, there is neither cancer, nor struma, nor syphilis, nor mercurial erethism to contend with, the case will generally end in a cure. It is probable that such cases are seldom watched from beginning to end by those who have described them, and that they have therefore sometimes been erroneously judged incurable merely on account of their tediousness.

Dr Simpson had met with cases somewhat similar, in which, after sneezing, the patients expelled casts of the nostril. He had not thought of diseased bone as the cause, but one of his patients had necrosis of the lower jaw. Dr Robert Hamilton, Dr Begbie, Dr Wright, and Dr Kerr likewise stated the results of their experience in ozœna, and other diseases of the nasal cavity.

\section{INFLAMMATORY ERUPTIONS UPON THE MUCOUS MEMBRANE OF THE CERVIX}

\section{UTERI. BY PROFESSOR SIMPSON.}

The common forms and effects of inflammation of the cervix uteri, viz. ulceration, hypertrophy, and induration of the cervix, were now well known 
to the profession. But the surface of the cervix was liable to other types of inflammation of an eruptive character, which apparently had hitherto been little, or not at all, studied by obstetricians; and were not yet described in works upon the pathology of uterine diseases. Among these special inflammations of the cervix uteri and top of the vagina, Dr Simpson had observed eruptions referable to the vesicular, pustular, tubercular, papular, and erythematic orders of the classification of Willan and Bateman. Herpes (herpes uterinus) he had seen following the usual course of herpes labialis in two or three instances, in patients who had months previously been under treatment for common ulceration of the cervix ; and Dr S. suggested that perhaps this and other eruptions were occasionally the origin and basis of the common variety of granular cervical ulcer. Acne, in the form of chronic, hard tubercles and pustules, was by no means uncommon, and often co-existed with common ulceration. A papular form of eruption sometimes supervened in chronic cases of uterine disease, and was usually diffused over both the cervix uteri and interior of the vagina ; sometimes having the characters of Lichen; in other instances presenting the appearances and severe itching symptoms of Prurigo. Eczema and patches of Apthoe also occurred. The treatment required to be varied according to the nature and character of the eruption, and consisted of the application of nitrate of silver, of medicated washes, and medicated pessaries, \&c. In severe and distressing cases of prurigo of the cervix, vagina, and vulva, brushing the affected surface often with hydrocyanic acid (the strength of that of the Edinburgh Pharmacopœia), was mentioned as often giving the greatest relief.

Dr Pattison mentioned a case of prurigo of the vulva, which Dr Simpson had seen with him, and where the hydrocyanic acid had at once afforded perfect relief.

\section{EDINBURGH OBSTETRICAL SOCIETY.}

SESSION IX.

Meeting III.-February 13, 1850.-Dr Srmpson, President, in the Chair.

CASES OF TETANUS COMING ON AFTER ABORTION. BY DR A. WOOD AND DR MALCOLM.

Mrs C., aged about 36,-stout make-florid complexion-after menstruation had been obstructed for three months, was seized, on the 16th November 1845, about three A.M., with copious coloured discharge from the vagina without pain. When seen at seven A.M., countenance pale; pulse quick and weak; discharge abundant, and mixed with coagula ; uterus enlarged ; os uteri flattened, and slightly open. The vagina was plugged, and sugar of lead and opium were given. The plug was removed in two hours by the nurse, on account of the uneasiness which it caused. On the 17th, the discharge, which had been abundant all yesterday, increased to-day, and was accompanied with large quantities of coagula; os uteri sufficiently open to admit the finger; the uterus seems full of coagulated blood. Under treatment the discharge abated, and in a few days she was so far recovered that Dr Wood took leave of her. On November $23 \mathrm{~d}$, he received a hurried message to see Mrs C. in the evening, but being detained with a bad case of labour, did not see her until November 24 th, at seven A.M. He found that the bowels had not been open since the 25th; had been complaining all day of stiffness of the jaws and sore throat, for which Dr James Simpson, the family medical attendant, who had seen her in his absence, had prescribed fomentations of camomile flowers. The stiffness of the jaws was considerable, and they were opened with such difficulty, that it was impossible to see the throat; pulse 80 , soft, and compressible. In the forenoon the bowels were freely opened by a turpentine enema; the stiffness of the jaws had, however, increased ; acute pain in the spine was complained of ; the abdominal muscles were stiff, and swallowing difficult. A sedative draught was 
now administered. On again visiting her in the evening, $\mathrm{Dr} \mathrm{W}$. found that no relief had been obtained from the draught. She had had a tetanic spasm at six P.M. ; and while visiting at seven P.M., a second occurred. She could no longer swallow. Professor Syme was now consulted. Injections with tobacco, Indian hemp, and opium were prescribed, but the convulsions continued to increase in frequency, and she died at ten A.M. on the 26 th.

In Dr Malcolm's patient, tetanus supervened upon a severe attack of cynanche tonsillaris, with which the lady was seized upwards of a fortnight after she had suffered from abortion at a very early period of pregnancy, and from which she had satisfactorily recovered. When Dr Malcolm was first called to see this lady, she was suffering from inflammation and ulceration of the cervix, but had not the least suspicion of being in the family way. The treatment of this state of the uterus was commenced in the usual manner. In a few days, however, she was taken with the symptoms of abortion, which speedily followed. In the course of about a fortnight, she had recovered so far that the usual daily visit was discontinued. About this time, having taken some liberty with herself, she caught cold. The cynanche tonsillaris was severe; and on the second day it was accompanied, as often happens, with inability to move the jaw. On the third day, the symptoms were all very much aggravated, but presented no peculiarity. On the fourth day, she still continued very feverish and ill, and about noon she was seized, for the first time, with general tetanic spasms. She was seen in this fit by several physicians in the absence of Dr M. When Dr M. called the fit had ceased. After two hours the tetanic spasms returned with increased violence, and did not cease till she died in the course of a few minutes.

Dr Simpson observed, that he had seen a patient die of tetanus after a uterine lesion, but not after abortion. In the case he referred to, and which Professor Syme saw with him, a very large soft cellular polypus was detached and thrown off by the spontaneous efforts of the uterus. A few days subsequently the patient had difficulty in opening her mouth. She died in the course of about fifty hours, with all the symptoms of general tetanus. In some of the Registrar-General's Reports on the Causes of Death in England, two cases of death from tetanus after child-birth are noticed.

Dr Duncan stated, that in the number of the "Monthly Journal of Medical Science" for December last, there was contained an abstract of a paper by $\mathbf{M}$. Pitre-Aubinais on puerperal tetanus after child-birth. It deserved the attention of the Society.

CASE OF ACCUMULATED AND RETAINED MENSTRUAL SECRETION.

BY PROFESSOR SIMPSON.

Dr Simpson exhibited to the Society a very large quantity of a thick viscid fluid, of a dark red colour, which had been removed that day by $\mathrm{Mr}$ Syme from a young woman in the Royal Infirmary.

The girl was nineteen years of age, had never menstruated in the usual way, and made great complaints of severe pains in the back and loins, which were much exacerbated every three or four weeks. About five months ago she was for the first time sensible of a swelling in the hypogastrium about the size of the fist. Since then it had gradually increased, but chiefly at the periods of the monthly exacerbations. On examination, the hymen was found perfect and entire, and the vagina and uterus greatly dilated, by the accumulated menstrual secretion. The hymen was divided by Mr Syme, and the fluid exlibited was evacuated.

Dr Simpson stated that the same operation had been performed by him in the Maternity Hospital, in a case where the cause of occlusion was adhesion and contraction of the vagina from sloughing, following a previous difficult labour. The quantity of fluid evacuated was almost as great. This patient, like many others who underwent this apparently simple operation, had suffered 
under a smart attack of irritative fever after it. Dr Ramsbotham had collected five or six cases, in which this irritative fever had gone on to a fatal termination.

Dr Keiller mentioned a case operated on by Dr Webster of Dundee, in which the collection of fluid was even greater than in the case operated on by $\mathrm{Mr}$ Syme.

NEW FORM OF OBSTRUCTION IN HEAD PRESENTATIONS FROM POSTERIOR DISPLACEMENT OF THE ARM. BY PROFESSOR SIMPSON.

Dr Simpson stated that he considered the case to which he wished to direct the attention of the Society an important one, because the peculiar obstruction in head presentations, which it illustrated, was, so far as he knew, hitherto undescribed. The form of obstruction consisted in one of the arms of the infant being displaced backwards across the neck or occipital region ; or more properly speaking, it

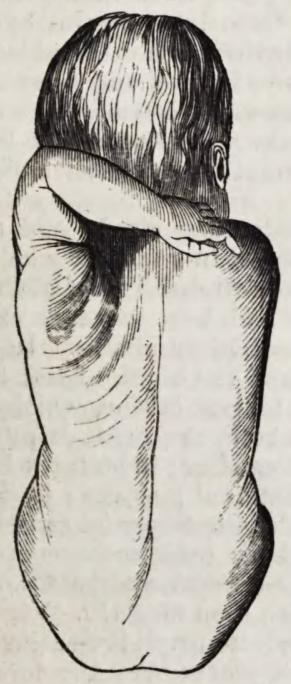
was the forearm that was thus thrown across the back of the head and neck, the arm being thrown upwards in a line with the body, in order to admit of this malposition of the forearm. In this abnormal position the displaced elbow and forearm of the child, first increased greatly the dimensions of the basis of the head; and secondly, these same parts formed a kind of projecting obstruction, which readily hitched and caught upon the brim of the pelvis, thus preventing the descent of the head. But the effects might be better judged of by detailing the case itself.

The patient had previously borne nine children. All the labours had been easy, and she had frequently been delivered so speedily, that the labour was over before the medical attendant could reach the house. In her last and tenth labour, pains came on about four in the afternoon, and the os uteri was not completely opened up till about ten o'clock. About an hour before, the membranes ruptured. At six next morning, Dr S. received a note from her medical attendant, Mr Carmichael, asking him to see her, as the head had remained in the same position at the brim for several hours, the uterine contractions were becoming weak, and the woman herself exhausted. On placing the patient deeply under the influence of chloroform, in order to make a complete examination, Dr S. found the maternal passages perfectly relaxed and open, and the head of the child to be by no means large, and not even entirely filling up the brim. The vertex presented, and the face was directed towards the left sacro-iliac synchondrosis, - a rare enough position, but one not in any degree calculated to account for the delay. On passing the examining fingers farther upwards, in order to trace any possible obstruction, Dr S. touched a projecting body (the elbow) beyond the left ear of the child; and on now making the examination more carefully, he traced this body backwards across the neck of the infant, and found it to consist of the left forearm of the child thrown back posteriorly behind the head. Dr S. then brought the hand downwards and forwards, believing that if it were converted into a head and arm presentation, the case might terminate without further interference. During the next half hour, however, the pains, which had for some time been weak, had little effect in forwarding the presenting parts, and as the child's heart had now sunk as low as 78 beats in the minute, Dr S., in order to preserve the child, again chloroformed the patient deeply, and delivered the child by podalic turning. The mother made a speedy recovery. The child soon cried strongly, and goes on quite well. Its left arm was for a day or two 
after delivery easily thrown into the position described. The occipito-frontal circumference of the head was afterwards measured by Mr Carmichael, and found to be $14 \frac{1}{4}$ inches; when the arm was placed in its anomalous position, the same circumference measured $15 \frac{1}{2}$ inches. The circumference of the shoulders was $13 \frac{1}{2}$ inches. The child was of about the usual size, and weighed $7 \frac{1}{4} \mathrm{lbs}$.

The Treatment of such a cause of obstruction, when it was once recognised, should probably consist of bringing the hand downward and forward over the side of the head, so as to convert the case into one of simple presentation of the head and arm. Perhaps it might occasionally be possible to push the elbow forwards in the direction of the lower end of the sternum, and thus draw back the displaced arm into its normal position in front of the chest. If either of these measures proved impossible, or failed, then the podalic version would be required.

The Diagnosis of the case was the most difficult point in its management. And in this, as in other complications-as detention from intra-uterine hydrocephalus, \&c. - the assistance of anæsthetics in midwifery was invaluable as a means of enabling the accoucheur to make a far more effective, and searching, and successful manual examination and diagnosis, in cases of obstructed labours, than it was possible to do when the patient was awake and incapable of bearing with steadiness, and without unnecessary suffering, the introduction of the hand for the purpose.

When a labour, as in the preceding case, notwithstanding steady and continued uterine contractions, becomes morbidly prolonged in a mother who had previously borne easily a large family, there was every probability of obstruction of some kind on the part of the infant. Dr S. had seen two such cases, where the detention was the result of intra-uterine hydrocephalus. In the present instance it was the result of the malposition of the hand. Some time since he had mentioned to the Society two cases of tedious labour, which, several years ago, he had seen with Dr Ziegler : in both, the head, despite of strong pains, remained in the pelvic brim without descending; in both the head was evidently not disproportionately large to the maternal passages; in both some point of the shoulder or arm could be touched by the finger on examination; and, perhaps, if the examination could have been made more complete by the use of ether or chloroform, which were then unknown, a malposition of the arm, similar to the one above described, might have been detected. Various cases are recorded of obstructed labours, with the head, as usual, presenting, in mothers who had previously had natural deliveries, and where the forceps failed to extract the child, and where even extraction after craniotomy was difficult. Some of these cases were in all probability instances of obstruction from dorsal malposition of the arm, or rather of the forearm. The late Dr Campbell, shortly before his death, told Dr S. of a case where there was no pelvic or other deformity on the part of the mother, no want of uterine contraction, and no disproportionate size of the head of the child, and yet he and others had entirely failed in extracting the detained infant by the forceps, and at last were obliged to open its head.

When looked for, Dr S. believed, therefore, that the dorsal malposition of the forearm would be found a more frequent cause of obstructed labour than the total silence of obstetric authors on the subject might, a priori, lead us to suppose. Further, he considered the present case as interesting, not only as an instance of an undescribed species of malposition and obstruction, but probably as one of a new class of malpositions as yet unrecognised in any of our accounts of the mechanism of labour, and the malpositions of the child. It would probably be found that other degrees and forms of malposition of the arm might occasionally lead to the same result.

Dr Cumming said that he had a distinct recollection of the case mentioned to Dr Simpson by Dr Campbell. The late Mr John Kennedy had been in attendance on the patient during the greater part of the night. The labour had advanced regularly and naturally till the os uteri was of tolerable width, and 
the vertex had descended some way into the pelvis, then, though the pains continued sufficiently powerful, though the head of the child was quite moveable, and the soft parts of the woman were perfectly relaxed, no further advance was made. About mid-day Mr K. sent for Dr Cumming, expressing himself unable to account for the arrest of the labour. On examination, Dr C. found matters exactly as they had been described, and was at first disposed to account for the retardation by the hand being tilted up under the chin ; but on further consideration abandoned this idea, as in all the cases he had seen of delay from this cause, the head had descended deeper into the pelvis than in this case. Mr K. and Dr C. waited on for several hours, during which various efforts were made to ascertain the cause of arrest; but as these were unavailing, as the pains were becoming more inefficient, and tenderness of the abdomen was threatening, they resolved to apply the forceps. The instruments were accordingly applied without difficulty, and $\mathrm{Mr} \mathrm{K}$. used all the exertion he thought justifiable, but without the slightest effect. Dr C. then made similar exertions equally fruitless. After a time $\mathrm{Mr}$ K. resumed, and Dr C. again followed him, but with the same result. At this stage they deliberated as to their next course of procedure. The head had not advanced in the slightest degree in spite of all their traction; it was still quite unimpacted and moveable. There was no discoverable contraction of any of the dimensions of the pelvis. It was the third or fourth pregnancy, and in her previous labours the patient had had nothing uncommon, certainly nothing instrumental. What could be the cause of arrest ? They confessed themselves fairly baffled, and sent for Dr Campbell, who lived in the neighbourhood, and who, with his usual kindness and promptitude, was soon at the bed-side. On his first examination, he was inclined to think that his less experienced friends had been premature in their resort.to the instruments, and hinted disapprobation. Operations were therefore suspended till he should see the effect of the pains. He was soon satisfied that, for the woman's sake, if not for the child's, the use of the forceps was advisable. They were applied, and he pulled at first with great caution and forbearance, but with the same result as his friends. To shorten the details, the three doctors pulled in succession with all the force they thought justifiable, but without effecting the slightest advance. The state of the woman now indicated that no further delay should take place. Dr Campbell accordingly used the crotchet, and the delivery was soon accomplished. Dr Cumming has no distinct remembrance of what occurred after the extraction of the head, nor is he aware that there was any mark about any portion of the child to indicate the cause of detention. In subsequent conversation, it was confessed that to all the three doctors it was a mystery; but Dr Cumming said that he could well believe it to have been such a case as that so distinctly and satisfactorily made out by Dr Simpson. Had the chloroform then been in use, the examination might, and probably would, have been made with more boldness, freedom, and success.

Dr Simpson observed, that sometimes, in women who had previously borne a large family, a cause of obstruction might exist in a late labour, not on the part of the child, as was generally the fact, but on the part of the uterus. Last summer he saw, with Dr Skae, a case of this kind, where the source of detention was a firm and contracted circular band of the uterus around the site of the neck of the child.

LINGERING LABOUR FROM A STRICTURE OF THE UTERINE PARIETES AROUND THE CHILD'S NECK.

Dr Skae stated that accidental stricture of the uterus during labour, and especially before the separation of the placenta, as a consequence of irregular or spasmodic contraction of its walls, was an occurrence by no means unfrequently met with ; but the following case of uterine stricture was one of quite a different character. The contraction was of a permanent kind, and probably had been developed in the course of utero-gestation, offering an insuperable barrier to the progress of labour, so far as the effects of antispasmodic 
treatment could be brought to bear on it. Its relation, indeed, to accidental stricture is so similar to that between accidental and unavoidable hemorrhage as to warrant its being called unavoidable stricture. The patient in whom it occurred complained of a feeling of tightness across the lower part of the abdomen during the three last months of gestation, and had a strong impression on her mind that all was not right with her, for she had on no former occasion experienced the same feeling, although she had had a large family, and once or twice twins. The particulars were as follows :-

Dr S. was sent for by Mrs C. on the morning of Tuesday, the 12th of June last, as she thought herself in labour. Examination discovered no indication of incipient parturition, and an opiate, followed by castor oil, was prescribed, on the supposition that the pains, which were said to have been steady and severe for some hours, were of the ordinary character of the spurious pains which so frequently precede labour. Notwithstanding repeated opiates, however, the pains abated but little during the subsequent forty-eight hours, when dilatation of the os uteri began to show itself. During the whole of Thursday the 14th, labour progressed favourably, so far as dilatation of the os was concerned ; but it was only about four or five o'clock that the presentation could be distinctly made out, when the head could be found to descend to the brim during the pains. The patient continued suffering, apparently from severe labour pains, with but little change in the position of the foetal head till past midnight. The head descended, during the pains, to the brim of the pelvis, but never entered it, although an attempt was repeatedly made to steady it in its most favourable position for descent. Edema of the os uteri now showed itself, and the strength of the patient began to flag. Dr S. therefore made two or three attempts to bring her under the influence of chloroform, but unsuccessfully, for she resisted with all her strength, being firmly determined not to take it; and his only assistant was an elderly female, who was worse than useless from alarm and agitation. By this time he felt satisfied that the obstruction to labour must be of some unusual kind, for the pelvis was large and well formed, and the size, firmness, and configuration of the child's head opposed the idea of hydrocephalus. He therefore sent for Dr Simpson, at two A.M., and they succeeded in speedily putting her under a full dose of chloroform, when the cause of obstruction was found to depend on the presence of a rigid stricture, situated in the lower third of the uterus, upon which rested the shoulders of the fœtus. After administering 120 drops of Sol. Mur. Morphia, and keeping her pretty deeply under the influence of chloroform for two hours, it was found that no material relaxation of the stricture had taken place, to admit of turning without endangering the integrity of the uterine walls. It was feared that evisceration might be ultimately necessary, but employment of the long forceps was resolved upon, notwithstanding the unusual difficulty of applying them so high up, as necessarily to require their being locked within the vagina. Dr Simpson, however, with his accustomed tact and dexterity, succeeded not only in applying them, but also in accomplishing delivery in some fifteen or twenty minutes, by dragging the shoulders of the fœetus through the stricture. In this case both mother and child did well, the recovery being unattended by any unfavourable symptoms.

[The remainder of the report of Meeting III. will be given in our next.]

THE LATE DR JOHN REID.

Professor Bennetr, on concluding his description of the functions of the eighth pair of nerves, addressed the class of the institutes of medicine as follows :-

Gentlemen,-As in the case of Sir Charles Bell with the fifth nerve, so with Dr John Reid and the eighth nerve, it is only by contrasting the confusion that existed before, with the positive knowledge which resulted from his researches, that we can form a just idea of their importance. During the course, I have had 
many occasions to mention the name of Dr Reid, but I seize on the present one as perhaps the most appropriate which has occurred to me since his death, for saying a few words with regard to his labours and scientific merits.

Dr Reid possessed a singularly penetrative and sagacious mind, which he brought to bear with the most advantageous results on all the various subjects which engaged it. As a physiologist, he may be considered to have been unsurpassed, not, indeed, because it has fallen to his lot to make those great discoveries, or wide generalisations which constitute epochs in the history of the science, but because he possessed such a rare degree of caution and conscientiousness in all his researches, that no kind of investigation, whether literary, anatomical, physiological, or pathological, that could illustrate any particular fact, did he ever allow to be neglected. In pursuing his own inquiries, also, he was ever most careful to do every possible justice to preceding and contemporary writers, whilst the modest manner in which they were brought forward, although in opposition to those of men of established reputation, so far from irritating their self-love, almost always led to a friendship between them. The various public positions he held as a teacher presented him with admirable opportunities for becoming thoroughly acquainted with the different facts in anatomy, physiology, and pathology, and it was from the study of these sciences, in union with each other, that he derived the great reputation which he latterly possessed.

I first knew him in 1833, at which time he was demonstrator to Dr Knox, who had then one of the largest anatomical classes ever formed in this country. It was Reid's habit to remain in the dissecting room daily, from nine in the morning till four in the afternoon. At one o'clock he gave a demonstration at one of the tables on some dissection that happened to be made by a student. We used to crowd round him, and ask questions on any point that was not thoroughly understood; but this was very seldom necessary, for such was the order, clearness, and minuteness of his description, that the subject was indeed made easy to the dullest comprehension. That kind of instruction also which, with him, as with every great anatomist of this country, sought for illustration in those points bearing on surgical or medical practice, was never lost sight of; and I for one, up to this hour, and I firmly believe, on this account, have never forgotten his admirable demonstrations on the anatomy of the neck, axilla, groin, and other regions of the body. Such was the commencement of Reid's career, and the means by which he obtained that thorough knowledge of anatomy which was so important in his future proceedings. About this time he published several anatomical papers; one on the Injections of the Vessels of the Fœtus, to show some of the peculiarities of its Circulation; another on the Structure of the Mesenteric Glands in the Balænoptera Rostrata; Observations on Phlebolites, and some others.

We next view him as a lecturer on physiology, he having succeeded Dr Fletcher in the extra-academical school of this city in that capacity. His lectures were compiled with infinite care, and he introduced into them, for the first time in Edinburgh, numerous experiments on living animals. Even in his hands, however, such illustrations did not prove attractive, and gradually he ceased to perform them. But it was as a teacher of physiology that he was naturally led to consider a variety of obscure subjects, and among the rest the extraordinary confusion that existed as to the functions of the three divisions of the eighth pair of nerves. He determined on carefully investigating their function experimentally, and having first made himself master of all that was known in connection with it, he planned and executed a series of experiments which, for ingenuity, dexterity of performance, exact description, and the cautious and accurate deductions he made from them, have never been surpassed in this or any other country. Such as we have seen are the multiplicity of branches and anastomoses connected with the eighth pair, that in endeavouring to irritate and cut across one branch, the others are extremely liable NEW SERIES. - NO. IV. APRIL 1850. 
to be injured. In every case, therefore, having recorded the phenomena observed, he took care, after the death of the animal, to make a careful dissection of the parts, in order to satisfy himself and others that the nerves operated on were really what he supposed them to be. During this laborious inquiry, which extended over a period of two years, he performed upwards of one hundred experiments, and numerous dissections, and the whole were so well planned, so carefully performed, and so judiciously considered, that in no one of his inferences has he ever been proved to be incorrect. His experiments have been repeated by many of the most able and dexterous anatomists and physiologists of Europe, all of whose inquiries have only served to confirm his results. On one occasion, indeed, a discrepancy arose between Reid's observations on the vagus and those of Longet; for the latter physiologist says, that by irritating the root of this nerve no movements can be produced in the muscles of the larynx or of the pharynx ; whereas, Reid states that such irritation does cause movements. The circumstance, however, that a white cord passes over the superior ganglion of the nerve, as shown by $\mathrm{Mr}$ Spence, which afterwards joins the spinal accessory, renders it almost certain that motor filaments are associated with those forming the root of the vagus. It is therefore more probable that Longet was in error (perhaps from the sensibility of the nerve being exhausted in the auimals he experimented on), when he says that the vagus is a purely sensitive, and the accessory a purely motor nerve ; and that the nerves furnishing the laryngeal and pharyngeal muscles are derived from the latter.

You must not imagine, however, that this was the only contribution Reid made to physiology, although certainly it was the principal one. His papers " On the Relation between Muscular Contractility and the Nervous System"- "On the Order of Succession in which the Vital Actions are arrested in Asphyxia""On the Effects of Venesection in Renewing and Increasing the Heart's Action under Certain Circumstances"- "On the Effects of Lesion of the Trunk of the Ganglionic System of Nerves in the Neck upon the Eyeball and its Appendages," and many others, are all characterised by their great value in elucidating obscure physiological phenomena, by their uncommon clearness and accuracy in the statement of facts, and by the exactness and caution of the deductions they contain. Indeed, every thing he published has a merit peculiarly its own, for it may be said that, although slow to arrive at a decision, whenever he had really made up his mind on any disputed point, you may be pretty well assured that his conclusion was the correct one. During his last illness he busied himself in revising and writing his various papers, which have been published in a separate volume, - a book I cannot too strongly recommend to your perusal, as containing more original matter, and more sound physiology, than will be found in any work that has issued from the British press for many years.

But we have next to consider him as a pathologist, for after having taught anatomy and physiology in the manner described, he was appointed, in 1839, Superintendent and Pathologist to the Royal Infirmary. He now made all the post-mortem examinations in that institution, and carried into his inquiries concerning morbid anatomy and pathology, the same accuracy in observing facts, and the same cautious spirit in drawing inferences from them, that characterised his anatomical and physiological researches. He at once saw the necessity of making his position serviceable to the advancement of medical knowledge ; and struck with the inconsistencies which existed as to the absolute and relative size and weight of the principal organs of the body, he commenced another laborious investigation on this subject. He introduced weighing machines into the pathological theatre, by means of which the weight of the entire body was first ascertained, and then respectively the weights of the different organs. In this way he ascertained the weight of the entire encephalon, of the cerebrum and cerebellum, with and without the pons varolii and medulla oblongata, in 253 subjects. He also weighed the heart, liver, and the two kidneys, in 142 subjects ; and from the whole inquiry he published some most useful tables as to the average weight of these organs. He also published 
a valuable paper on "The Pathology of the Continued Fever of Edinburgh," founded on forty-seven post-mortem examinations of individuals who had died of that disease. It was in this communication he made the singular observation, that during the ordinary Edinburgh fever, no intestinal ulcerations occurred, and pointed out the fact, that when such lesion was found, the individual came from a distance.

He published other valuable pathological papers ; but it mnst be confessed, he regarded pathology more with the eye of a physiologist than of a practitioner; and histology being then in its infancy, was of very little service to him. But the knowledge he acquired of morbid anatomy, and with the anormal relations of parts, has perhaps never been surpassed.

During the period he was pathologist to the Royal Infirmary, there was introduced under his superintendence that regular method of inscribing the leading facts connected with each case in a register, which has since prevailed; and he it was who compiled the first series of statistical tables published by the managers. He was always very sanguine with regard to the important results which would flow from statistics applied to medical cases ; and although experience has not fulfilled his anticipations, there can be no doubt that under his auspices a more perfect system of registration, and more correct tables, were formed, than had previously existed within any large hospital.

It was in 1841 that he was appointed Chandos Professor of Anatomy in the University of St Andrews. Here there was no medical school, properly so called-no hospital-no subjects for dissection-no bodies to examine. Deprived of the conversation of his former fellow-teachers in medicine, and of the stimulus to inquiry which such conversation tends to produce, it was still necessary for him to find a subject for original inquiry, on which to expend his mental energies. The bay of St Andrews is celebrated for its marine productions, and, seizing on the advantages which lay within his reach, he commenced another phase in his scientific career, and became a naturalist. Having obtained one of Chevalier's best microscopes, he studied histology, and was soon acquainted with the minute structure of animals. He studied the habits and mode of development of the mollusca, crustacea, and fishes in the adjacent seas. He dredged for them off various parts of the coast. $\mathrm{He}$ kept many animals in his house for years, and minutely watched their manner of reproduction; and, at the same time made himself master of all that had been written regarding them in this and other countries. It was not long before he began to add papers of great importance to the science of zoology, among which may be mentioned, "Anatomical and Physiological Observations on Some Zoophytes," "On the Development of the Ova of the Nudibranchiate Mollusca," and "Observations on the Development of the Medusa, and an Account of a New Actinia." One of his latest memoirs was on some remarkable structures found in the "Vagmaer,"-a fish of such rarity that only one specimen of it, and that a very imperfect one, was ever examined in this country, but which he immediately recognised and described.

Thus in all the relations in which Dr Reid stood as a man of sciencewhether as anatomist, physiologist, pathologist, or zoologist-we observe in him the same habits of cautious inquiry, the same ability and excellence, the same power of extending the boundaries of knowledge, the same sagacity and perception of the true. It is impossible to calculate the splendid results that such a man might have achieved, if, instead of being cut off at the early age of forty, his life had been prolonged. Even as it was, there were few living whose opinions were so much respected, or who interfered with greater effect to expose an error, or to support a truth. As a proof of this, I may mention that when Dr Burrows' work was published, in which it wasattempted to be shown that the views of Monro, Kelly, and Abercrombie, respecting the peculiarity of the circulation within the cranium were fallacious, I placed, as the then Editor of the Monthly Journal, the book in his hands for review. The result was, as we have seen, such a complete refutation of Dr Burrows' argument, that no an- 
swer has been, nor is it likely ever will be, made. Indeed, judging from what Reid had accomplished, and from his thorough knowledge of everything he studied, I think there can be little doubt that he would ultimately have obtained a reputation equal to that of any British anatomist or zoologist.

But not only was the entire life of Reid one of great usefulness to science, but the kind and manner of his death was also destined to be very instructive, and that in two-most important points of view.

The advance of pathological histology had naturally turned the attention of medical men to the undoubted fact, that many growths, essentially different in their nature, were commonly confounded together under the term "malignant." Lebert and others had separated certain diseases, consisting of an hypertrophy of the epidermis and epithelium, from cancerous growths, strictly so called, although they had long been called cancer by surgeons. These sonamed cancers of the lip, face, and os uteri, however, were known to heal and undergo permanent cures after excision; but similar sores on the tongue were considered unusually liable to return. It was one of the last that caused the death of Reid; for all the surgeons whom he consulted, and in whom he placed confidence, united in dissuading him from having recourse to an operation. I cannot, at present, enter into all the details of the case,- - suffice it to say that the ulcer in the tongue spread; a lymphatic gland on the right side of the neck became enlarged; he suffered the most excruciating agony from the ulcer affecting those very nerves, the functions of which his own labours had so greatly tended to elucidate. Though at this time fully prepared for death, he was aware of the epithelial as distinguished from the truly cancerous nature of the disease, and, as a last resource, his old friend, Mr Fergusson, of London, during a visit he paid Edinburgh, in August 1848, excised the portion of the tongue affected.

The wound healed rapidly, he regained his general health from the moment of the operation, the agony he experienced ceased, and he frequently told me, that the operation, were it only to be considered as a palliative, was to him most invaluable. He became very anxious, however, respecting the glands in his neck, and insisted on their removal, which was accomplished as thoroughly as possible by Dr Duncan, on two separate occasions, although their deep-seated connections render it doubtful whether complete extirpation had been accomplished. For a time all went well, but in the early part of the summer of 1849 , the edges of the incisions in the neck assumed an unhealthy appearance, the disease spread inwards towards the tongue and oesophagus, and he died in the following July. His case, then, was the first that clearly demonstrated that a local epithelial disease might produce a similar alteration of structure in the lymphatic glands, and prove fatal in the manner of so-called malignant growths. He himself frequently conversed with me on the subject, and suggested that the affection should be denominated epitheloid cancer. It would altogether be out of place to enter at present on the numerous interesting considerations to which this case gives rise in a medical point of view. I need only observe, that it is my intention, with his expressed consent, to publish it at length, as it furnishes a most important series of facts in connection with the subject of morbid growths.

But there is another point of view in which his death may be regarded. I allude to the undaunted courage with which he himself met it as a philosopher, and the resignation with which he bowed to its power as a Christian. Perhaps there were few men better qualified than himself to judge of the danger and necessarily painful nature of a malignant disease in the throat, involving such important nerves; and nothing could be more unaffectedly sincere than his fortitude, nor more evident than the depth and influence of his religious convictions. I visited him a fortnight before his death; his neck was covered over with purple, nodulated seams; he calmly squeezed the cheesy matter from the sinuses which had formed, and conversed about his case as if he were an unconcerned party. He told me that neither then nor at any time since the first operation, did he ever suffer the excrueiating 
kind of pain that he had done, when the disease was seated in the tongue. He repeatedly thanked me for having strongly advised the operation, and presented me with some of the vertebral cartilage of the Vagmaer, which exhibits a peculiar structure, as a parting present. He enjoined me carefully to examine his body after death, and if I thought it useful, to publish the result, at the same time assuring me that he was fully prepared to die. He strongly pointed out the importance of all persons forming correct views of, and earnestly attending to, religion, lest death might come suddenly, and so deprive them of the advantage, as he expressed it, which had been accorded to him, of preparing for the immortality beyond it.

I have only further to say, that John Reid was entirely free from that petty jealousy and morbid sensitiveness which are too often found united with otherwise strong mental powers. There was no dogmatism, nothing overbearing; but, on the contrary, the greatest indulgence for the errors or inferiority of others, and a ready willingness to oblige and instruct whenever he could be of service. He owed nothing to those external accomplishments and elegancies which attract the regards of society. His refinement was of a deeper character, and depended wholly upon kindness of heart, unswerving rectitude, and an earnest love of truth,- qualities for which his personal friends esteemed him beyond measure, and to which the scientific world is indebted for his admirable and exact labours.

Gentrimen,- - I am sure you will acquit me from the charge of often entering into prolix details, interesting stories, or unmeaning declamations, foreign from the branch of science it is my duty to teach. Should you think that I have done so on the present occasion you will attribute it partly to my long friendship for the subject of this notice, to whom I was anxious to pay some tribute, however unworthy of him; and partly because his career, his mode of research in science, the respect with which he was regarded hy his contemporaries, and the reputation he has left as a physiologist, are eminently entitled to your attention, and to the regards of all those who are actuated by a sincere desire to advance the boundaries of human knowledge.

\section{MEDICAL RELIEF OF THE POOR IN SCOTLAND.}

The Fourth Annual Report of the Board of Supervision announces, that the distribution of the first parliamentary grant of L.10,000, in aid of medical relief in Scotland has been completed. Only 438 parishes and combinations have established their claim to participation in the grant, by producing vouchers for the required amount of expenditure from their own funds. The aggregate amount of the sums apportioned to the parishes, which, for the present, have either declined to participate or made no claim, has been apportioned to the parishes which have established their claims, in sums proportioned to their actual vouched medical expenditure on medical relief in the last year.

"Medical relief for the poor, which, before the recent statute came into operation, parochial authorities hardly recognised it as a part of their duty to provide, has continued since 1845 to increase in efficiency; and, with the aid of the parliamentary grant, may now, there is reason to hope, be placed upon a satisfactory footing. The expenditure for this purpose, which in the year ending February 1846 was L.4,055, had, in the year ending May 1848, increased to L.30,339. In this latter sum, however, as we stated in our third report, the cost of nutritious diet and other supplies, not strictly chargeable under the head of medical relief, were in many cases included. The sum returned as expended in the year ending May 1849 is L.33,010, 12s. 11 $\frac{1}{2}$ d., from which all expenditure, not strictly chargeable as medical relief, was, by our directions, excluded. While, therefore, the apparent increase is about L.2,671, the actual increase must be much more considerable, although we have not the means of 
ascertaining its precise amount. On the other hand, the charges under this head have been augmented, during the past year, by the measures which a large proportion of the parochial boards adopted in consequence of the prevalence of cholera.

" The sum expended on medical relief last year, L.33,010, is equal to threepence per head on the population of Scotland in 1841. Of this ainount, ninetenths of a penny per head having been covered by the parliamentary grant, the expenditure from the local funds has been equal to twopence and one-tenth of a penny per head on the population. In 1845 the expenditure was about fourtenths of a penny per head on the same population. Simultaneously with this increase of expenditure, there has been a progressive advancement towards a more systematic and efficient provision of medical relief for the poor, and a manifest desire on the part of a considerable majority of the parochial boards to fulfil their obligations. When it is remembered that only five years ago this description of relief was not provided at all, except in a few parishes, it will be admitted that the parochial boards generally have not been slow to remedy the deficiency; and although there are still many parishes in which we cannot venture to represent this department of relief as being efficiently provided for, and few parishes in which it is administered with as much regularity and method as would be desirable, or as might have been attained without additional cost, we cannot doubt, where so much has already been effected in so short a time, that we shall have the ready co-operation of a great majority of the parochial boards in carrying out the rules by which we have endeavoured to give more uniformity and regularity to the system, and to place its administration under such checks as may afford the parochial authorities and the public a reasonable security that the duty is adequately performed."-Fourth Annual Report of Board of Supervision, 1849.

\section{TRIAL FOR FRAUDULENTLY OBTAINING A SURGEON'S DIPLOMA.}

On Monday, the 11th instant, the melancholy spectacle was presented of two respectable-looking persons arraigned at the bar of the High Court of Justiciary, on the charge of having obtained, by fraud, in the name of one of them, a diploma from the College of Surgeons of Edinburgh. It appeared from the evidence, that one of them, William Duncan, in the year 1844, was practising at Amble, in Northumberland, and that the other, Alexander Cumming, acted as his assistant; that before that time Duncan had been often twitted with having no diploma, and that in the end of that year, soon after Cumming's return from a short absence, Duncan began to show about a diploma from the Edinburgh College of Surgeons. The diploma had been recovered by the authorities, and was produced in Court. It was in all respects regular, being granted in the name of William Duncan, and regularly signed, while it bore date the 4th of December 1844. It was, however, proved that Duncan, on that day, had not left the neighbourhood of Amble. It appeared further, from the evidence, that, though Duncan had no diploma up to December 1844, he had certificates of having regularly gone through the course of study required to qualify for the examination by which the diploma is obtained, and that Cumming carried these to Edinburgh, and, personating Duncan, was admitted to examination, and, having passed, obtained that diploma in Duncan's name, which was exhibited to the Court. It appeared from the evidence, that the candidate for a diploma from the Edinburgh College, besides exhibiting his certificates, is required to draw up a schedule of his whole course of study, which he authenticates with his signature, and that these schedules are preserved by the College, being bound up in volumes. Accordingly the schedule of study given in by Cumming, for the purpose of obtaining an examination on the 4 th day of December 1844, was produced in the Court, bearing the name of William Duncan, which signature Cumming was charged with forging. 
The charge of forgery, we believe, was departed from, but the evidence of fraud was complete.

The trial occupied the Court between six and seven hours, several points of law being argued in the course of it. Among these was an objection to the competency of the Court to try Duncan, who had committed no offence in Scotland. The Court gave no decision on its own competency to try the whole case ; but directed Duncan to be acquitted on a technical difficulty in the indictment. Cumming was, however, found guilty, and sentenced to imprisonment for one year.-Medical Times, March 16.

\section{MURDER BY A MANIAC.}

Mr Wilson, a medical practitioner in the village of Juniper Green, near Edinburgh, and his mother, who resided in the same house with him, were, on the night of Sunday the 17th ultimo, murdered by a lunatic, for whom Mr Wilson was in the habit of prescribing. We spare our readers the details of the mode in which the double murder was perpetrated. Our chief object, in alluding to it, is to impress upon them the fearful responsibility which rests with any party who permits a dangerous lunatic to go at large and unguarded, merely because his mischievous paroxysms are not of frequent occurrence. We trust that the horrible occurrence at Juniper Green will convey a useful lesson.

\section{VARIETIES.}

Curnical Medicine.-The course of Clinical Medicine in the University is likely to receive much benefit from certain arrangements lately made by the Medical Faculty. One of the disused clinical wards is to be opened for the reception of cutaneous diseases, and another for those peculiar to women and children. Professor Simpson has consented to take charge of the latter, and the Faculty has authorised his giving clinical lectures to the students of the University.

Hahnemann's Organon.- " Have you ever looked into Homœopathy? Have you ever read Hahnemann's Organon ?" said an eminent divine to an equally eminent physician. "No," replied the physician; "And let me ask you in return, if you have read the Mormon Bible?" The gentleman, of course, answered in the negative ; and his medical friend said to him very properly, "When you take the trouble to examine Joe Smith's Bible, I will take the trouble to examine Hahnemann's Organon."-Physician and Patient.

Medical Literature.-A candidate for a professorship in Paris quoted Morgagni among other great literary names in his thesis, but unfortunately quoted him wrong. This did not escape one of his opponents, who, on attacking it, said that he had attributed to Morgagni an error of which he was innocent, and which he would not have done had he read his works. In reply, it was stated, that he could not read Morgagni, because he did not understand English! "A thousand pardons, Monsieur, if you do not understand English it is altogether different. Let us speak of something else." It is said that the judges would have been more satisfied with this candidate had he only known a little English.-Gazette des Hôpitaux, February 19, 1850.

A Democratic Thesis.-A student of Medicine in Berlin has lately written a thesis "De Morbo Democratico, nova Insania Formâ," which has caused a great sensation among a certain class of politicians in that city.-L'Union Médicale, February 28, 1850.

Prize A warded for Etherisation.- Out of the sum (L.2,000 annually) which the bequest of M. Monthyon enables the Academy of Sciences in Paris to dis: 
tribute for the encouragement of the medical and natural sciences, there has been voted this year to Dr Jackson and Mr Morton L.100 each, for the discovery of the anæsthetic properties of ether.

London Professional Jeatousy.-In the "Lancet" for 9th March ultimo, appeared an engraving of Dr Simpson's well-known instrument for supporting a retroverted uterus, which an anonymous correspondent of that journal affected to be unacquainted with, and proposed to call the "Infernal Uterine Machine."

The Liston Testimonial.-The sum subscribed towards this object amounts to L.750, which, being insufficient for the erection of a statue, it has been decided that four busts should be executed-one to be placed in the Royal College of Surgeons, another in University Oollege, London, a third in the Royal Infirmary of Edinburgh, and a fourth to be presented to the family of the deceased.-Medical Gazette, March 8, 1850.

Origin of Medical Degrees among the Practitioners of England.-From a statement of Mr Sheppard, based on the accounts in the London Medical Directory, it would appear that there are 554 persons in London with a medical degree, obtained as follows :-From Edinburgh, 178 ; foreign universities, 93; London, 66; St Andrews, 68 ; Cambridge, 41 ; Glasgow, 35 ; Oxford, 25 ; Aberdeen, 30; Dublin, 11. In the provinces the total number is 1091 ; and of these there are obtained from Edinburgh, 533; St Andrews, 120; foreign universities, 114 ; Glasgow, 105 ; A berdeen, 68 ; London, 58 ; Cambridge, 57 ; Dublin, 21; Oxford, 15.-Provincial Journal, Feb. 5, and Mar. 6, 1850.

Private Treatment of Skin and Venereal Diseases.-It has been determined to set aside a certain number of private rooms at the $\mathrm{St}$ Louis and Venereal Hospitals in Paris, for the treatment of individuals who, without being poor, are still unable to be treated satisfactorily at home. -Two franes a-day is to be demanded for the accommodation.-Bulletin Gen.de Thérapeutique, February 28, 1850. [A similar arrangment is much required in Edinburgh, as many skin diseases, requiring numerous baths, and that superintendence which can only be properly afforded in well-directed institutions are prevalent in the city.]

Value of Surgery in the North of England. - The following advertisement appeared in the "North British Advertiser" of the 16th ultimo :- " Wanted immediately, in the north of England, an Experienced Surgeon, who can Amputate, and Manage Accidents, \&c Salary L.25 per annum, with Board and Lodging. No inexperienced young man need apply" !

\section{BOOKS RECEIVED.}

Transactions of the American Medical Association. Vol. ii. Philadelphia : 1849.

Hastings considered as a Resort for Invalids. By James Mackness, M.D. London : 1850.

Some Account of the Last Yellow Fever Epidemic of British Guiana. By Daniel Blair, M.D, Surgeon-General of British Guiana. Edited by Dr John Davy. 8vo. London : 1850.

The Hunterian Oration for 1850 . By Frederick C. Skey, F.R.S. London: Churchill. 1850.

The Principles and Practice of the Water Cure. By Rowland East, Surgeon. London: 1850 .
The Cholera; What has it Taught us? By W'illiam J. Cox, M.R.C.S.E., London : 1850.

The Chrono-Thermalist. No. I. London : 1850.

Outlines of Medical Proof. By Thomas Mayo, M.D. London: 1850 .

The Accommodation of the Eye to Distances. By William Clay Wallace, M.D. New'York : 1850.

Descriptive Catalogue of Works in Science and General Literature. (Published by Taylor, Walton, and Maberly.) London: 1850.

An Appeal to the Public in Behalf of an Hospital for Sick Children. London: 1850. 